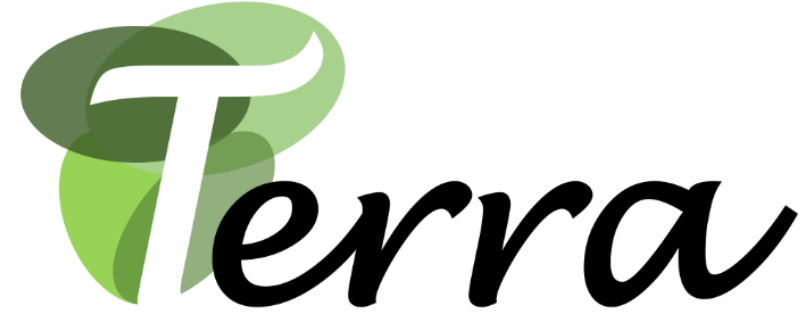

Revista de Desarrollo Local

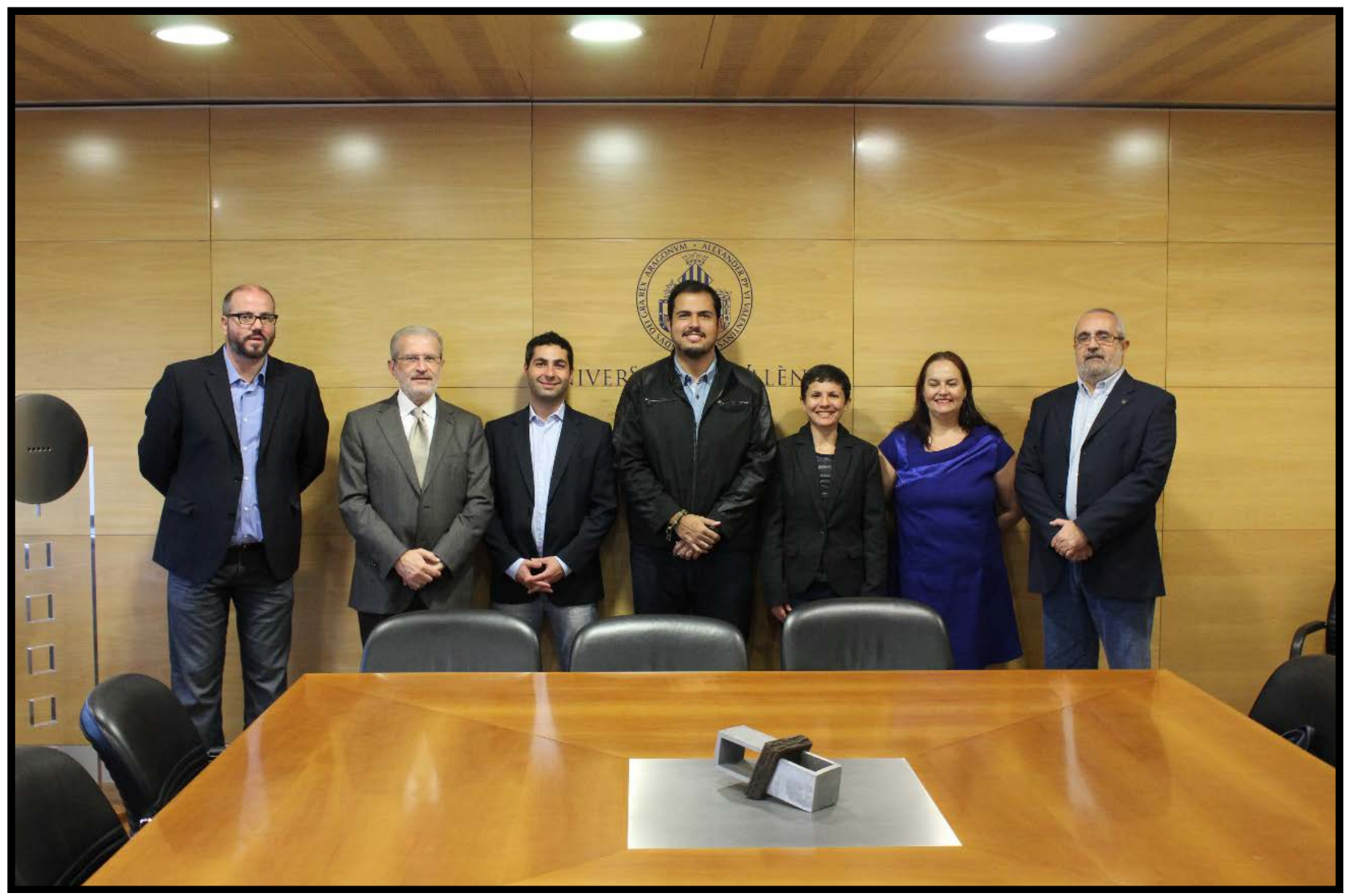

- Homenaje a Joan Noguera Tur -

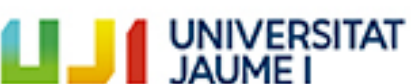

Institut Interuniversitari de Desenvolupament Local

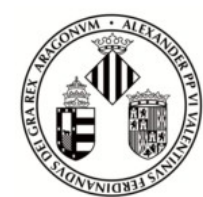

VNIVERSITAT

(B) ValènCia 
TERRA. Revista de Desarrollo Local e-ISSN: 2386-9968

Número 8 (2021), 678-690

DOI 10.7203/terra.8.20470

IIDL - Instituto Interuniversitario de Desarrollo Local

\title{
Jornades sobre Desenvolupament Local de la \\ Comunitat Valenciana (JDL): una bona pràctica de transferència al territori potenciada des de l'IIDL
}

\author{
Ricard Calvo \\ Grup d'Investigació en Desenvolupament Territorial de la Universitat de València \\ (GRIDET) i Comitè Organitzador de les JDL-CV \\ Ricardo.Calvo@uv.es
}

\section{Mónica Bou}

Grup d'Investigació en Desenvolupament Territorial de la Universitat de València (GRIDET) i Comitè Organitzador de les JDL-CV

Monica.Bou@uv.es

\section{Enric Sigalat}

Grup d'Investigació en Desenvolupament Territorial de la Universitat de València (GRIDET) i Comitè Organitzador de les JDL-CV

Enrique.Sigalat@uv.es

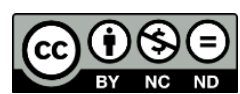

Esta obra se distribuye con la licencia Creative Commons Reconocimiento-NoComercial-SinObraDerivada 4.0 Internacional 


\section{SECCIÓN EXPERIENCIAS Y BUENAS PRÁCTICAS}

\section{Jornades sobre Desenvolupament Local de la Comunitat Valenciana (JDL): una bona pràctica de transferència al territori potenciada des de l'IIDL}

Resum: Una bona pràctica per al territori. Joan Noguera era sabedor de que la proposta de Jornades sobre Desenvolupament Local de la Comunitat Valenciana (JDL) cobrien un espai existent, no ocupat fins aquell moment. Era una necessitat. Les JDL naixien amb una vessant científica molt important. El seu propòsit va ser des d'un principi erigir-se com a un espai científic (investigadors), acadèmic (professorat i estudiants), professional (principalment AEDL) i social (per a personal interessat en general). I en eixe aspecte, l'IIDL , com a institut referent a nivell universitari (interuniversitari entre la Universitat de València i la UJI de Castelló), especialitzat en la matèria , era necessari que se sumara al projecte. Al present text presentem l'experiència desenvolupada als darrers 10 anys, així com els resultats més destacats que s'han obtès a les mateixes (nombre de participants, experiències presentades, llibres publicats, entitats participants, i, continguts de les JDL -ponents, perfil ponents, taules debat, etcètera.-) i resultats que han convertit a aquesta experiència en una bona pràctica generadora de transferència al territori.

Paraules clau: Joan Noguera, Jornades sobre Desenvolupament Local de la Comunitat Valenciana, JDL, GRIDET-Grup d'Investigació en Desenvolupament Territorial de la Universitat de València, Territori.

Recibido: 02 de junio de 2020

Devuelto para revisión: 15 de febrero de 2021

Aceptado: 17 de febrero de 2021

\section{Referencia / Citation:}

Calvo, R., Bou, M., y Sigalat, E. (2021). Jornades sobre Desenvolupament Local de la Comunitat Valenciana (JDL): una bona pràctica de transferència al territori potenciada des de l'IIDL. TERRA. Revista de Desarrollo Local, (8), 678-690. DOI 10.7203/terra.8.20470 


\section{INTRODUCCIÓ}

Unes paraules molt evocadores van ser les que Joan Noguera ens va remetre per a l'acte d'inauguració de les VI Jornades sobre Desenvolupament Local de la Comunitat Valenciana (VI JDL 2016), dedicades al "Desenvolupament Local sostenible i ocupació verda". En la citada edició, demanàrem als representants de les entitats que donaven suport a les Jornades que ens enviaren un vídeo curt -de no més de 3 minuts-, on exposaren la seua visió del desenvolupament local d'acord amb el concepte de desenvolupament sostenible. A continuació, recollim literalment les paraules que ens va enviar Joan Noguera:

"JDL 2016. En primer lloc donar les gràcies a l'organització. Saludar a tots i totes les persones assistents a aquestes jornades que ja van sent llegendàries sobre desenvolupament local no a soles de la Comunitat Valenciana sinó també de més enllà del nostre territori. Estic en vosaltres des del meu refugi particular per a contestar unes senzilles preguntes que l'organització em demana sobre com està la situació del desenvolupament sostenible en l'actualitat. Bé, ni hi ha més teoria que practica, hi ha més voluntat que fets $i$ ni hi ha més coneixement que pràctica com deia en l'àmbit de polítiques i programes que efectivament estiguen desenvolupant processos sostenibles de desenvolupament local.

Són molts els motius que ajuden a explicar aquesta situació però el motiu fonamental és que ni des del punt de vista social ni des del punt de vista de l'actuació de les institucions públiques estem encara preparats com a societat ni com el govern que la representa per a dur endavant les iniciatives que no són complexes, tan sols requereixen certa determinació i una mirada més enllà del dia a dia, o de la que permeten les baralles o les disputes del moment i fer una mirada més enllà, més estratègica. Quan açò es planteja d'aquesta manera, tota la picabaralla política que es produeix en l'escala local pot quedar en un segon terme en relació amb els assumptes que es poden pactar com un referent, d'una línia estratègica a seguir per part d'un territori. Tant poquet i tant com això és el que es necessita per assolir un desenvolupament local sostenible. La participació ciutadana necessària continua sent un seguit de processos inacabats, mal orientats en moltes ocasions, $i$ que contribueixen a desanimar i frustrar a la població en conter d'aconseguir implicar-la realment en processos simples, o el número més gran de processos possibles però efectius $i$ que donen peu a una vertadera participació no tan sols a escenaris, diguem-ne cinematogràfics de participació.

Espere que en els pròxims anys tant per part de les autoritats públiques com per part de la ciutadania hi haja una voluntat expressa $i$ major per apostar per metodologies $i$ processos de participació d'enfocament estratègic que permeten avançar en certa manera cap endavant d'una manera més sostenible. El nostre territori sens dubte ho necessita i ho necessita en molta urgència. Moltes gràcies de nou a l'organització han sigut unes reflexions en veu alta molt ràpides però ací estic dia a dia intentant donar una xicoteta aportació perquè açò algun dia es convertisca en realitat a força d'insistir en unes idees que sempre, sempre, sempre són les mateixes des de ja fa molt de temps i que el que ens cal és aplicar-les i ferho en tota la seua intensitat i en tota la seua dimensió. Que tingueu les millors jornades possibles i que tingueu molt bon dia. Vinga! Fins aviat!" 
Sens dubte, emotives paraules, i que amb el pas del temps han adquirit més importància de la que inicialment van tindre, atès que van ser unes de les últimes intervencions de Joan com a director del IIDL en un acte públic. Però no són paraules únicament plenes d'emoció i de fervor pel desenvolupament local, sinó que són paraules que demostren compromís amb el projecte GRIDET i amb la seua bandera emblemàtica, les Jornades sobre desenvolupament local de la Comunitat Valenciana (més conegudes com a JDL). Va ser a 2012 quan li vàrem proposar que l'IIDL participara com a partner de les JDL de manera més activa, era necessari que un institut com el nostre, especialista en la matèria, participara. Proposta que va acceptar immediatament, embarcant-se i implicant-se de manera directa en les mateixes (“...què necessiteu?, recorde ens va dir...”).

\section{LES JORNADES DE DESENVOLUPAMENT LOCAL}

\subsection{Les Jornades de Desenvolupament Local: propòsit i objectiu}

L'objectiu principal de les Jornades és reflexionar sobre la importància del desenvolupament local i el territori i presentar les aportacions de professionals i estudiosos sobre la matèria en l'àmbit de la Comunitat Valenciana. A la vegada que ser un punt de trobada d'intercanvi d'informació, coneixements i retroalimentació al voltant del desenvolupament territorial, fomentant també l'esperit de participació de qualsevol amb inquietuds al voltant del territori.

En síntesi, els objectius de les JDL com a punt de trobada entre l'àmbit professional, acadèmic i ciutadà, són:

- Transmetre al conjunt de la societat la importància dels aspectes que han de veure amb el desenvolupament territorial i donar a conèixer diferents iniciatives i intervencions que es realitzen tant en l'àmbit professional (tècnic) com en les Universitats i altres centres de coneixement.

- Dotar als participants de coneixements teoricopràctics necessaris per al desenvolupament del treball del desenvolupament local des del seu àmbit.

- Posar en comú i debatre els últims avenços teòrics i pràctics realitzats per diferents grups d'investigació d'àmbit nacional i/o internacional, així com del territori valencià.

- Difondre el treball que molts tècnics i estudiosos realitzen per a potenciar el desenvolupament econòmic i social del territori.

- Donar a conèixer els treballs que diferents professionals realitzen, promovent l'intercanvi d'experiències i coneixements.

- Reflexionar sobre els avantatges i dificultats del model de desenvolupament local valencià, amb la finalitat d'analitzar i establir mecanismes que faciliten un major progrés de les intervencions per al territori.

- Constituir, ampliar i/o consolidar les relacions professionals entre els diferents participants.

- Promoure entre els assistents l'esperit crític davant el repte que suposa l'estudi del desenvolupament local i intentar albirar la necessitat d'una constant formació teòricapràctica per a un bon acompliment de les iniciatives a desenvolupar.

Amb les JDL, buscàvem que la universitat com a estament acadèmic, tornara a posicionarse com un referent per al col·lectiu professional, per a la comunitat científica i per a les 
administracions públiques en matèria de desenvolupament local. Les temàtiques de les JDL han respost a necessitats detectades, bé perquè van ser plantejades pels participants en edicions anteriors, aportades a les enquestes de satisfacció realitzades a aquest efecte i/o bé de les rodes de consulta prèvia fetes amb les entitats col-laboradores. Les Jornades han volgut buscar i/o trobar què s'estava fent des de la pràctica, des del territori, intentant superar la visió tradicional limitada. Una visió etnocèntrica. És per això que la nostra intenció d'intervenir sobre la realitat, de facilitar eines que permeten en els territoris promoure actuacions més adequades a la seua realitat i les seues necessitats. Hem intentat fer un pas més enllà aportant idees i temàtiques en el debat-que si bé en un primer moment poden ser llunyanes o complexes- no obstant això, contenien un component estratègic.

Taula 1. Jornades desenvolupades 2010-2019

\begin{tabular}{|c|c|c|}
\hline Edició & Data realització & Temàtica \\
\hline I JDL 2010 & 16 i 17 desembre 2010 & Presente y futuro del desarrollo local \\
\hline II JDL 2011 & 15 desembre 2011 & $\begin{array}{c}\text { Nuevos escenarios para el desarrollo local: políticas de } \\
\text { empleo, innovación y responsabilidad territorial }\end{array}$ \\
\hline III JDL 2012 & 13 desembre 2013 & $\begin{array}{c}\text { Clústers d'ocupació: noves oportunitats pel } \\
\text { desenvolupament del territori }\end{array}$ \\
\hline IV JDL 2013 & 12 desembre 2013 & $\begin{array}{c}\text { Cultura i participació pel } \\
\text { desenvolupament del territori }\end{array}$ \\
\hline V JDL 2014 & 11 desembre 2014 & $\begin{array}{c}\text { L'avaluació i la política, elements estratègics de futur per } \\
\text { al desenvolupament local }\end{array}$ \\
\hline VI JDL 2015 & 10 desembre 2015 & $\begin{array}{c}\text { Polítiques d'equitat, polítiques de desenvolupament : } \\
\text { sense equitat no hi ha desenvolupament }\end{array}$ \\
\hline VII JDL 2016 & 15 desembre 2016 & $\begin{array}{c}\text { Models socioeconòmics per a la gestió del } \\
\text { territori: cap a la sostenibilitat, l'ocupació i el } \\
\text { desenvolupament local }\end{array}$ \\
\hline VIII JDL 2017 & 14 desembre 2017 & El finançament del desenvolupament local i el seu retorn \\
\hline IX JDL 2018 & 15 novembre 2018 & $\begin{array}{c}\text { Ferramentes i experiències de planificació i innovació } \\
\text { territorial (I+D+i+T): obligats al canvi? }\end{array}$ \\
\hline X JDL 2019 & 14 novembre 2019 & $\begin{array}{c}\text { Coordinació institucional multinivell: una necessitat per } \\
\text { al desenvolupament del territori del segle XXI }\end{array}$ \\
\hline
\end{tabular}

Font: elaboració pròpia.

\section{RESULTATS I DISCUSSIÓ}

Aquestes 10 edicions de les Jornades sobre Desenvolupament Local de la C.V. han generat una sèrie d'outputs que considerem d'interés i que arrepleguem en les següents cinc categories: a) nombre de participants (inscrits/assistents); b) nombre d'experiències presentades; c) llibres publicats; d) entitats participants; i, e) continguts de les JDL (ponents, perfil ponents, taules debat, etc.)

Orientades a uns col·lectius molt identificats -professionals, professorat, investigadors, alumnat i societat en general-, les JDL han congregat al llarg d'aquests deu anys, a un nombre molt considerable de participants. Amb una mitjana de més de 150 inscrits i una 
assistència efectiva al voltant dels 100 participants, les Jornades sobre Desenvolupament Local, considerem que han complit amb el seu objectiu inicial de convertir-se en un punt de trobada periòdica, especialitzat i de referència per a aquests col-lectius. Tant és així, que molts d'aquests participants, es refereixen a les JDL com "les Jornades de desembre", no important tant la temàtica ni els continguts, sinó que romanen fixades al calendari d'any en any, convertint-se en una cita ineludible per a ells.

Hem estimat que la taxa de repetició dels assistents supera el $40 \%$.

Taula 2. Taula d'inscrits/assistents a les JDL

\begin{tabular}{|c|c|c|c|c|c|}
\hline Edició JDL & Inscrits & Assistents & $\begin{array}{c}\text { Nombre } \\
\text { professionals/ } \\
\text { assistents }\end{array}$ & $\begin{array}{c}\text { Nombre } \\
\text { universitats } \\
\text { /assistents }\end{array}$ & $\begin{array}{c}\text { Nombre } \\
\text { d'altres/ } \\
\text { assistents }\end{array}$ \\
\hline I JDL 2010 & 85 & 82 & 52 & 30 & - \\
\hline II JDL 2011 & 145 & 112 & 74 & 32 & 6 \\
\hline III JDL 2012 & 201 & 145 & 94 & 39 & 12 \\
\hline IV JDL 2013 & 174 & 73 & 35 & 22 & 11 \\
\hline V JDL 2014 & 146 & 95 & 62 & 22 & 36 \\
\hline VI JDL 2015 & 129 & 101 & 43 & 25 & 13 \\
\hline VII JDL 2016 & 122 & 98 & 40 & 21 & 17 \\
\hline VIII JDL 2017 & 111 & 100 & 66 & 38 & 28 \\
\hline IX JDL 2018 & 133 & 110 & 55 & 79 & 23 \\
\hline X JDL 2019 & 205 & 200 & 96 & & 2 \\
\hline
\end{tabular}

Font: elaboració pròpia.

Pel que concerneix la tipologia dels participants en les Jornades, en el següent gràfic es pot observar com des dels orígens han sigut unes Jornades que han estat un referent per als professionals.

No obstant això, al llarg dels anys pot observar-se com la participació de la comunitat universitària és una constant, equilibrant-se cada vegada més sobretot en els últims dos anys. En l'últim any de celebració de les Jornades, la xifra és que 4 de cada 10 dels participants formaven part de l'àmbit acadèmic-universitari.

Això últim considerem que és una bona notícia, ja que lliga amb el que en els seus inicis es pretenia amb la realització d'aquesta mena d'esdeveniments, que el món acadèmic i el món professional s'assentaren i compartir coneixements, propostes i discussions, per al cap i a la fi, realitzar progresses en els territoris a través de les retroalimentacions hagudes en les Jornades $\mathrm{i}$ en les publicacions d'experiències. Fent perquè tothom -com diu Joan Noguera- puga participar, així també, el nombre de participants que ni són professionals ni vénen del món universitari, any rere any va sent una constant. Humilment, pensem que a poc a poc i amb l'ajuda i col-laboració de moltes persones que fan possible tot açò, ho anem aconseguint. Ara per ara, les Jornades, ja comencen a posicionar-se com un referent per al col-lectiu professional i també per a acadèmics i estudiosos del desenvolupament local i del territori.. 
Figura 1: Participants àmbits professional i universitari en les Jornades (total, absoluts)

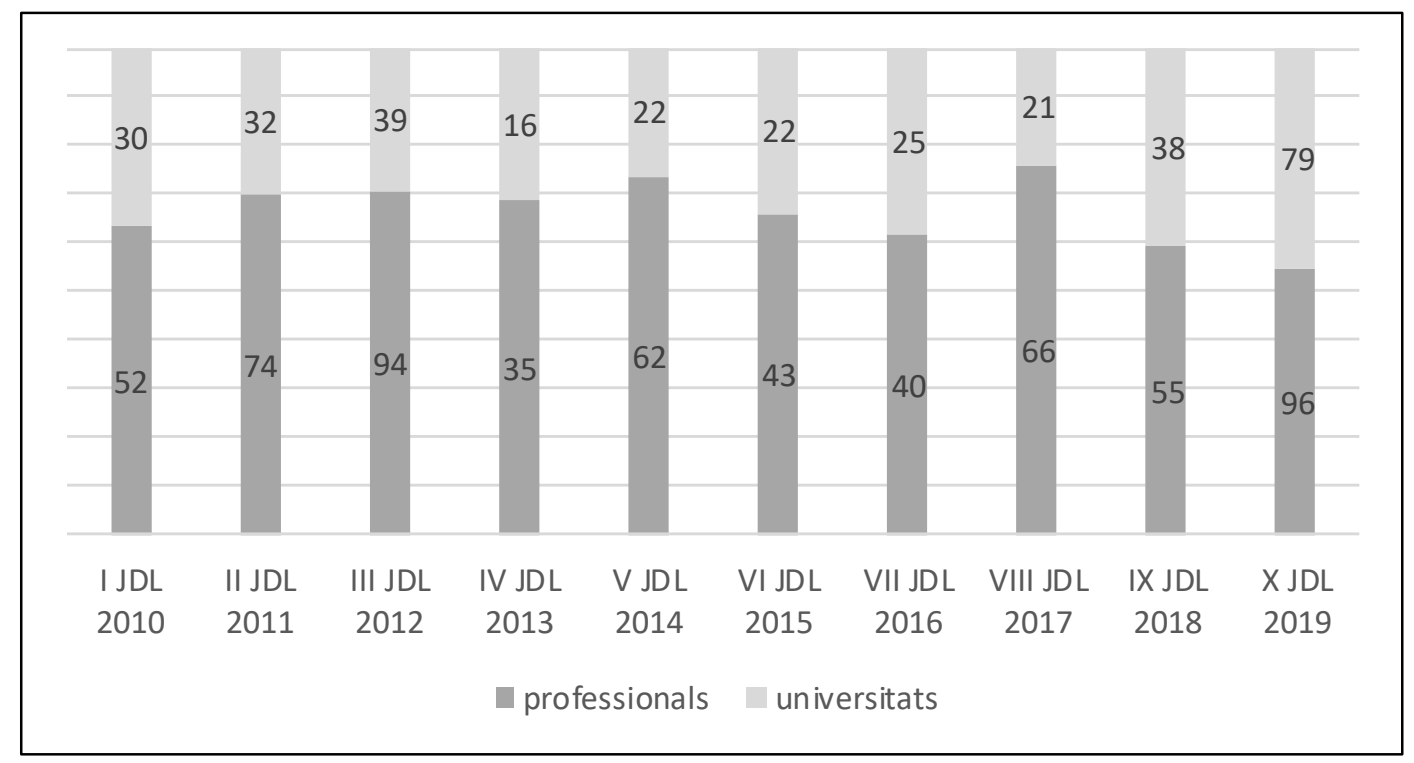

Font: elaboració pròpia.

De manera complementària, també ens sembla que una dimensió a tindre molt en compte en aquests resultats és certament, el nombre d'experiències presentades. En totes les edicions - des de la segona- s'ha obert un termini perquè aquelles persones interessades a compartir la seua experiència aplicada en el territori, la pogueren donar a conèixer en aquest entorn. La constitució d'un Comité Científic (format tant per acadèmics com per professionals), va permetre construir una columna vertebral que ha permès aportar una dimensió analítica així com del compliment d'uns requisits mínims que garantisquen una certa homogeneitat i qualitat dels textos (de les aportacions). Com podem veure al gràfic següent, de moment, comptem amb un total acumulat de 107 experiències han sigut recollides des dels inicis..

Figura 2: Nombre d'experiències presentades cada any a les JDL

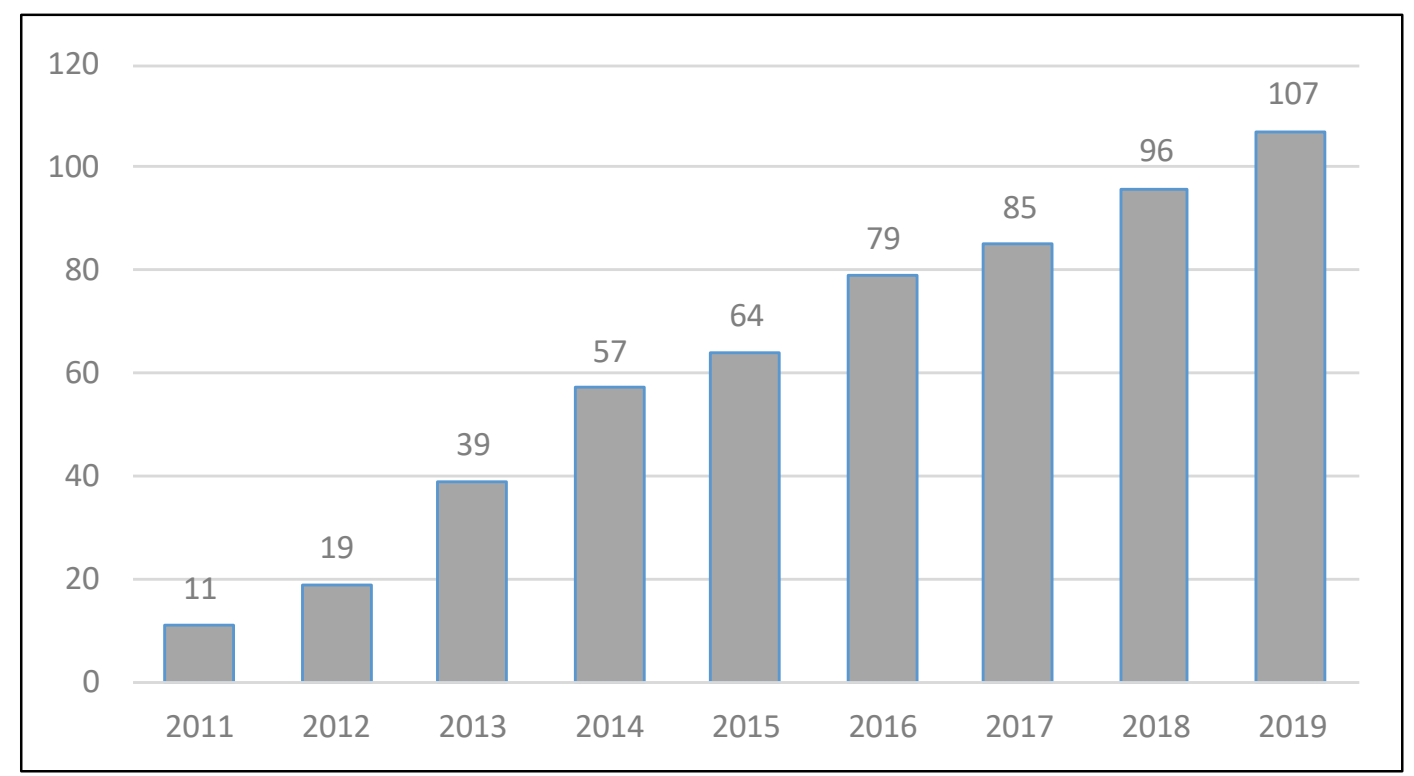

Font: elaboració pròpia. 
Pel que respecta a aquestes experiències, provenen principalment de l'àmbit autonòmic (per arrodonir, un 93\% d'elles), sent la resta -7 experiències- majorment de caràcter internacional, procedents de treballs realitzats per estudiants que han cursat els seus estudis de postgrau a la Comunitat Valenciana. I de les 106 experiències, quasi un 60 per cent han sigut aportades per tècnics i tècniques AEDL i/o experts/es en desenvolupament local que estan actuant sobre el territori. Un $29 \%$ per professorat i investigadors acadèmics, i la resta per estudiants de postgrau. De totes elles, més del $85 \%$ responen a experiències aplicades sobre el nostre territori. Pel que respecta al tercer dels resultats esmentats, els llibres publicats, les JDL han permès donar vida i continuïtat a una col-lecció pròpia i especialitzada en desenvolupament territorial. Denominada "territori i població" (t i p) ha anat recollint les experiències més destacades de les diferents edicions de les Jornades, tant de les aportacions dels ponents, com de les experiències presentades. Recollim a la taula següent tots els números publicats procedents de les Jornades.

Taula 3. Publicacions realitzades a les JDL ${ }^{1}$

\begin{tabular}{|c|c|c|c|c|}
\hline Any & Títol & ISBN & Col·lecció & Pàgines \\
\hline 2011 & $\begin{array}{l}\text { Nuevos escenarios para el desarrollo local: } \\
\text { políticas de empleo, innovación y } \\
\text { responsabilidad territorial }\end{array}$ & $978-84-92587-57-5$ & $\begin{array}{l}\text { vuit fulles } \\
5\end{array}$ & 228 \\
\hline 2012 & $\begin{array}{l}\text { Clústeres de empleo: nuevas oportunidades } \\
\text { para el desarrollo del territorio }\end{array}$ & $978-84-15660-34-7$ & t i p & 160 \\
\hline 2013 & $\begin{array}{l}\text { Ciudadanía empoderada: cultura } \quad \text { y } \\
\text { participación para el desarrollo local }\end{array}$ & $978-84-16044-25-2$ & t i p & 309 \\
\hline 2014 & $\begin{array}{l}\text { La evaluación y la política, elementos } \\
\text { estratégicos para el desarrollo local }\end{array}$ & $978-84-943435-2-0$ & tip 5 & 313 \\
\hline 2015 & $\begin{array}{l}\text { Políticas de equidad, políticas de desarrollo: } \\
\text { sin equidad no hay desarrollo }\end{array}$ & $978-84-16391-69-1$ & t i p & 143 \\
\hline 2016 & Desarrollo local sostenible y empleo verde & $978-84-16833-27-6$ & t i p & 323 \\
\hline 2017 & $\begin{array}{l}\text { El finançament del desenvolupament local i } \\
\text { el seu retorn }\end{array}$ & $978-84-16833-76-4$ & t ip & 120 \\
\hline 2018 & $\begin{array}{l}\text { Planificació i innovació territorial } \\
(\mathrm{I}+\mathrm{D}+\mathrm{i}+\mathrm{T}) \text {. ferramentes i experiències }\end{array}$ & $978-84-17464-29-5$ & $\mathrm{t} \mathrm{ip} 10$ & 169 \\
\hline 2019 & $\begin{array}{l}\text { Coordinació institucional multinivell: } \\
\text { reflexions i experiències des de la pràctica }\end{array}$ & $978-84-17464-71-4$ & t i p & 170 \\
\hline
\end{tabular}

Font: elaboració pròpia.

Com es pot veure a les figures anteriors, la temàtica que es convertia en l'eix principal de cada JDL ens va permetre recollir més o menys experiències del territori en cada edició. Totes aquestes activitats han tingut molt a veure amb les entitats que han col-laborat $\mathrm{i}$ patrocinat cadascuna de les edicions de les JDL, i que les han fet possible amb les seues aportacions econòmiques. En aquest sentit, i com podem veure al quadre següent, s'han anat incorporant totes aquelles entitats amb vinculació directa o indirecta amb el desenvolupament local. Entitats tan acadèmiques (Facultat Ciències Socials, Departament Sociologia, IIDL, Vicerectorat Participació i Projecció Territorial, Càtedra Cultura

\footnotetext{
${ }^{1}$ I que s'utilitza com a font de revisió documental per l'elaboració d'aquest article i que es pot consultar en l'apartat bibliogràfic.
} 
Territorial, Servei Política Lingüística, tots ells de la UV i el Màster DELEITE de la Universitat d'Alacant), com a professionals (Adlypse-CV Federació de Personal Tècnic en Gestió del Desenvolupament Local i Feprodel-Federació Estatal de Professionals del Desenvolupament Local), Administracions públiques (SERVEF-Labora-Servei Valencià d'Ocupació i Formació, Diputació de València, FVMP-Federació Valenciana de Municipis i Províncies, Pactem Nord, ValenciaActiva i Divalterra-Diputació de València), i l'entitat bancària valenciana Caixa Popular-SCV.

Taula 4. Entitats col• laboradores de les JDL

\begin{tabular}{|c|c|c|c|c|c|c|c|c|c|c|}
\hline Entitats & 슥을 & 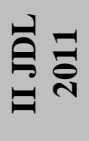 & 目空 & 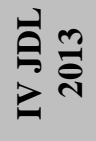 & 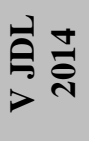 & 官 & 宣 & 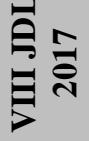 & $\underset{x}{\stackrel{\infty}{*}}$ & $\underset{x}{\vec{\partial}} \overrightarrow{\bar{N}}$ \\
\hline $\begin{array}{l}\text { Facultat Ciències } \\
\text { Socials (UV) }\end{array}$ & & & & & & & & & & \\
\hline $\begin{array}{l}\text { Departament } \\
\text { Sociologia (UV) }\end{array}$ & & & & & & & & & & \\
\hline Adlypse-CV & & & & & & & & & & \\
\hline $\begin{array}{l}\text { Diputació de } \\
\text { València (Form) }\end{array}$ & & & & & & & & & & \\
\hline Servef-Labora & & & & & & & & & & \\
\hline FVMP & & & & & & & & & & \\
\hline Iidl (UV) & & & & & & & & & & \\
\hline $\begin{array}{l}\text { Caixa Popular- } \\
\text { SCV }\end{array}$ & & & & & & & & & & \\
\hline Feprodel & & & & & & & & & & \\
\hline $\begin{array}{l}\text { Vicerectorat } \\
\text { Participació i } \\
\text { Projecció } \\
\text { Territorial (UV) }\end{array}$ & & & & & & & & & & \\
\hline $\begin{array}{l}\text { Máster DELEITE } \\
\text { (UA) }\end{array}$ & & & & & & & & & & \\
\hline $\begin{array}{l}\text { Cátedra Cultura } \\
\text { Territorial (UV) }\end{array}$ & & & & & & & & & & \\
\hline Pactem Nord & & & & & & & & & & \\
\hline ValenciaActiva & & & & & & & & & & \\
\hline $\begin{array}{l}\text { Servei Política } \\
\text { Lingüística (UV) }\end{array}$ & & & & & & & & & & \\
\hline $\begin{array}{l}\text { Divalterra (Diput. } \\
\text { de València) }\end{array}$ & & & & & & & & & & \\
\hline
\end{tabular}

Font: elaboració pròpia.

I per últim, encara que no menys important, des d'una perspectiva més qualitativa, cal referir-nos als continguts de les Jornades, qui i com s'han organitzat cadascuna de les edicions. La temàtica determinada com a central permet la recerca dels ponents més adients a la mateixa (experts coneixedors dels assumptes a tractar). La Jornada s'estructura 
en dues parts. Una primera part, on s'intenta mostrar i fer referència a plantejaments teòrics sobre el tema. Una segona part, aquesta més experiencial, que recull la selecció d'experiències desenvolupades en el nostre territori vinculades a la temàtica en qüestió.

Aquests aspectes queden arreplegats també a la següent taula, el primer pel que fa als ponents que han intervingut a les distintes edicions. Entre els que destaquem a Paco Alburquerque (Expert Internacional en Desenvolupament Local), Javier Esparcia (UVCátedra AVANT Antidespoblament), Francisco Álvarez (Especialista en Finances Ètiques i Director General d'Economia Social), Philippe Hatt (Director General en la Comissió Europea), Joan Ramon Sanchis (UV-Càtedra Economia del Bé Comú), David Pino (Director d'Innovació Social de l'Ajuntament de Sevilla), Pau Rausell (UV-Econcult i Codirector estratègic de la candidatura València Capital Mundial del Disseny), Miren Larrea (Orkestra-Institut Basc de Competitivitat), Josep V. Boira (Secretari Autonòmic de la Vertebració del Territori de la Conselleria d'Obres Públiques), Andrés García-Reche (Director General de l'Agència Valenciana de la Innovació -AVI), Ana Belén Sánchez (Especialista en Ocupació Verda de l'OIT per Amèrica Llatina), Francesc Colomer (Secretari Autonòmic de Turisme), Nieves Ramos (Federació d'Associacions Empresarials d'Empreses d'Inserció-FAEDEI), Antoni Such (Director General d'Administracions Públiques), Natxo Costa (Director General de Comerç), Rocío Briones (Directora General de LABORA), Joan Serafí Bernat (Director de l'Aeroport de Castelló) o el propi Joan Noguera (IIDL-València).

A més de la ponència central, les JDL s'han caracteritzat per donar la veu en primera persona a les experiències presentades en cada edició. A la següent taula, hem arreplegat les activitats desenvolupades a cadascuna de les Jornades.

Taula 5. Ponents, debats i experiències

\begin{tabular}{|c|c|c|c|c|c|}
\hline Any/edició & $\begin{array}{l}\text { Ponència } \\
\text { inaugural }\end{array}$ & $\begin{array}{c}\text { Altres } \\
\text { ponències }\end{array}$ & $\begin{array}{l}\text { Taula } \\
\text { debat }\end{array}$ & $\begin{array}{c}\text { Taula } \\
\text { experiències }\end{array}$ & $\begin{array}{c}\text { Presentació estudis, } \\
\text { investigació, llibres } \\
\text { premis,... }\end{array}$ \\
\hline I JDL 2010 & & & & & \\
\hline II JDL 2011 & & & & & \\
\hline III JDL 2012 & & & & & \\
\hline IV JDL 2013 & & & & & \\
\hline V JDL 2014 & & & & & \\
\hline VI JDL 2015 & & & & & \\
\hline VII JDL 2016 & & & & & \\
\hline VIII JDL 2017 & & & & & \\
\hline IX JDL 2018 & & & & & \\
\hline X JDL 2019 & & & & & \\
\hline
\end{tabular}

Font: elaboració pròpia.

\section{A MODE DE TANCAMENT}

Segons el que hem presentat es pot veure un grau de coincidència molt alt entre la proposta de les JDL (GRIDET) i de l' IIDL. Joan va apostar pel nostre projecte com a una bona pràctica per al territori. Per la transferència que podia generar, en considerar el 
nostre projecte com una experiència d'interès. A parer nostre, les JDL i GRIDET es poden considerar una experiència que genera transferència al territori pels següents motius:

1. Projecte col-laboratiu en essència. S'han anant sumant entitats amb implicació i interès en el desenvolupament socioeconòmic del territori. Es basen en la col-laboració i en l'obtenció d'un benefici mutu, de caràcter complementari, oferint-los directament l'oportunitat de participar en el projecte, superant així possibles diferències existents entre elles.

2. No ha buscat grans aportacions, si no el sumatori de xicotetes aportacions que permeten fer alguna cosa més gran i potent. Generació de relacions entre entitats vinculades que comparteixen un mateix objectiu: la millora del territori.

3. Un coneixement acumulatiu basat en una ampliació continua de les activitats realitzades, intentant cobrir les necessitats del territori. S'ha partit d'una necessitat existent, el que ha facilitat la seua posterior devolució al territori i la seua utilitat per al mateix.

4. Del desenvolupament local al desenvolupament territorial (visió més ampla). No s'ha limitat a aquesta accepció del terme, ni a la seua aplicació tan sols a les polítiques d'ocupació (programes de i per a l'ocupació). Superació dels límits tradicionals del desenvolupament local.

5. Transferència i accessibilitat. Distribució dels resultats, materials disponibles en obert, sempre accessibles.

6. Eco-eficiència. Part d'aprofitar el que ja existeix, no generant estructures paral-leles ni alternatives. Aprofitament dels recursos existents.

7. Triangulació de perspectives. Beneficis. Combinació de la visió acadèmica amb la professional (el mateix grup organitzador està conformat ja de manera mixta). Responent a visions d'interès tant per a professionals, acadèmics, investigadors, com personal interessat en general en el desenvolupament local.

8. Ha buscat deixar constància del treball realitzat pel model (bona mostra són les 106 experiències aportades a les JDL i arreplegades a les publicacions en aquests deu anys).

9. Projecte compromès amb el territori. Compta amb el territori en tot moment i per al mateix, sent l'últim destinatari últim de qualsevol iniciativa empresa.

10. Projecte co-participatiu. L'objectiu era compartir per totes les entitats participants. El procés de desenvolupament ha sigut molt participatiu, tractant-se temàtiques d'interès $\mathrm{i}$ actualitat que han despertat l'interès propi del col·lectiu.

\section{REFERENCIES}

Calvo, R., Bou, M., i Portet, J. (coords.) (2014). La evaluación y la política: elementos estratégicos de futuro para el desarrollo local. Alzira: Editorial Germania.

Calvo, R., Bou, M., i Portet, J. (coords.) (2015). Políticas de equidad, políticas de desarrollo: sin equidad no hay desarrollo. Alzira: Neopàtria.

Calvo, R., Bou, M., i Portet, J. (coords.) (2016). Desarrollo local sostenible y empleo verde. Alzira: Neopàtria. 
Calvo, R., Bou, M., Portet, J., Sigalat, E., i Martínez, J. D. (coords.) (2017). El finançament del desenvolupament local i el seu retorn. Alzira: Neopàtria.

Calvo, R., Bou, M., Sigalat, E., i Martínez, J. D. (coords.) (2018). Planificació i innovació territorial $(I+D+i+T)$. Ferramentes i experiències. Alzira: Neopàtria.

Calvo, R., Rodríguez del Pino, J. A., i Portet, J. (coords.) (2011). Nuevos escenarios para el desarrollo local: políticas de empleo, innovación y responsabilidad territorial. Alzira: Editorial Germania.

Calvo, R., Rodríguez del Pino, J. A., Bou, M., i Portet, J. (coords.) (2012). Clústeres de empleo: nuevas oportunidades para el desarrollo del territorio. Alzira: Editorial Germania.

Calvo, R., Rodríguez del Pino, J. A., Bou, M., i Portet, J. (coords.) (2013). Ciudadanía empoderada: cultura y participación para el desarrollo local. Alzira: Editorial Germania.

Sigalat, E., Calvo, R., Bou, M., i Martínez, J. D. (coords.) (2019). Coordinació institucional multinivell: reflexions $i$ experiències des de la pràctica. Alzira: Neopàtria. 